\title{
AE Signature Interpretation of Single Particle Crushing under Uniaxial Compression
}

\author{
Sha Luo $^{1,2, *}$ Erdin Ibraim $^{1}$, and Andrea Diambra ${ }^{1}$ \\ ${ }^{1}$ University of Bristol, Civil Engineering Department, Bristol, BS8 1TH, UK \\ ${ }^{2}$ University of Birmingham, Civil Engineering Department, Birmingham, B15 2TT, UK
}

\begin{abstract}
Granular soils exhibit particle crushing under certain loading circumstances, and it significantly affects their mechanical behaviour. However, the estimation of the particle crushing is extremely challenging. Therefore, new a technic based on passive non-destructive Acoustic Emission (AE) monitoring is explored to infer the extent and evolution of soil's particle size distribution. However, in this paper only individual particles under uniaxial compression are studied and the results should inform the interpretation of the laboratory tests on small scale soil samples. Different material types from rigid to soft and brittle to ductile are used in order to probe the AE characteristics and deduce the AE signature attached to various particle crushing mechanisms. The particle size and material type are the main parameters considered, and clear variation of the AE signal characteristics are detected. These encouraging findings on the use of AE monitoring system offer the possibility to identify the micro crushing event of soil particle in the macro soils.
\end{abstract}

\section{Introduction}

The significance of particle crushing to the mechanical behaviour of granular materials has been well identified by many studies and practice and is of interest to many disciplines including geotechnics, geology, geophysics, mining engineering and powder technology [1]. In the field of geomechanics, soil grain breakage frequently occurs if the confining stresses are sufficiently large. Such phenomenon is significant in a wide range of practical geotechnical applications involving shallow foundations [2], the soil around driven piles [3] and foundations of large offshore structures, embankment and dams [4], pavement and railway substructures. The particle crushing process induces changes in the soil's particle size distribution and alters the stiffness and strength of granular soil, while significant volumetric contractions are associated [5]. The understanding of the soil crushing mechanisms will directly affect the development and application of the mathematical models in representing the soil behaviour adequately [6]. The amount of soil breakage depends on particle mineralogy (internal structure, particle hardness), particle size and particle size distribution, particle shape, packing (density), state of effective stress, effective stress path and the presence or absence of water [6].

Acoustic Emission (AE) passive monitoring technique has already been used in various engineering applications, from the characterisation of the behaviour of rocks (in the 1930's) to metals (in the 1950's). The acoustic emissions are micro seismic events that occur on materials at small sample scale or large structural scale - during loading. The
$\mathrm{AE}$ events are recorded by a transducer or an array of transducers, and the data can complement other mechanical measurements of stress or strain by providing insight into various internal material phenomena. During 1960 's, several studies reported the use of the AE in geotechnical engineering as a suitable technique to provide such real-time data [7] in particular for the study of some fundamental phenomena, in small-scale laboratory tests [8], large-scale laboratory tests, slope stability monitoring in dams $[9,10]$ and embankments, seepage monitoring, and grout/hydrofracture monitoring. Acoustic emission generated by the collision of soil particles was also studied in order to infer their particle size and shape $[11,12]$. A direct correlation between $\mathrm{AE}$ rate and deformation of sandy soils in the triaxial testing conditions was found by [13], while Fast Fourier Transform (FFT) of the acoustic emission signals was used for the on-line control of hydro-abrasive erosion (HAE) processes [14].

The possibility of using Acoustic Emission for the characterisation of single particle breakage under uniaxial compression loading was tested in different studies [1517]. This paper explores further this research direction and compares the characteristics of the $\mathrm{AE}$ output for different particle type materials. The materials range from stiff to relatively soft particles, from brittle to ductile. The description of the $\mathrm{AE}$ particle crushing signature for different materials also considers the effects of particle size.

\footnotetext{
* Corresponding author: luosha23@msn.cn
} 


\section{Material \& Methodology}

\subsection{Material}

Four types of materials been collected for testing: glass sphere, silica sand, chalk and salt particles (Figure 1). The glass sphere is type M SiLibeads glass beads [18] and the silica particles are brown sand of Leighton Buzzard (LB) from Lower Greensand (UK). All these particles were washed and dried before the tests. The chalk particles resulted from crushed limestone from a quarry in Préfontaines (central France). The salt particles resulted from rock salt sourced from the Himalayan Mountains. The chalk and salt particles have also been dried in the oven for 24 hours at 105 Celsius before testing.

Moreover, the analysis of the shape of each tested particle has been conducted. There are different methods and a broad account of parameters to describe the particle shape. In this study, the following shape descriptors are used: the equivalent area diameter, $\mathrm{d}_{\mathrm{a}}$, the irregularity, IR, and the degree of circularity, C [19-21]:

$$
\begin{aligned}
& d_{\mathrm{a}}=(4 \mathrm{~A} / \pi)^{\wedge}(1 / 2) \\
& I R=\mathrm{d}_{\text {imax }} / \mathrm{d}_{\mathrm{cmin}} \\
& C=(4 \pi \mathrm{A}) /\left(\mathrm{P}^{2}\right)
\end{aligned}
$$

where $\mathrm{A}$ is the area of particle projection, $\mathrm{P}$ is the perimeter of the particle projection, $d_{\text {imax }}$ is the diameter of the maximum inscribed circle, and $\mathrm{d}_{\mathrm{cmin}}$ is the diameter of the minimum circumscribed circle.
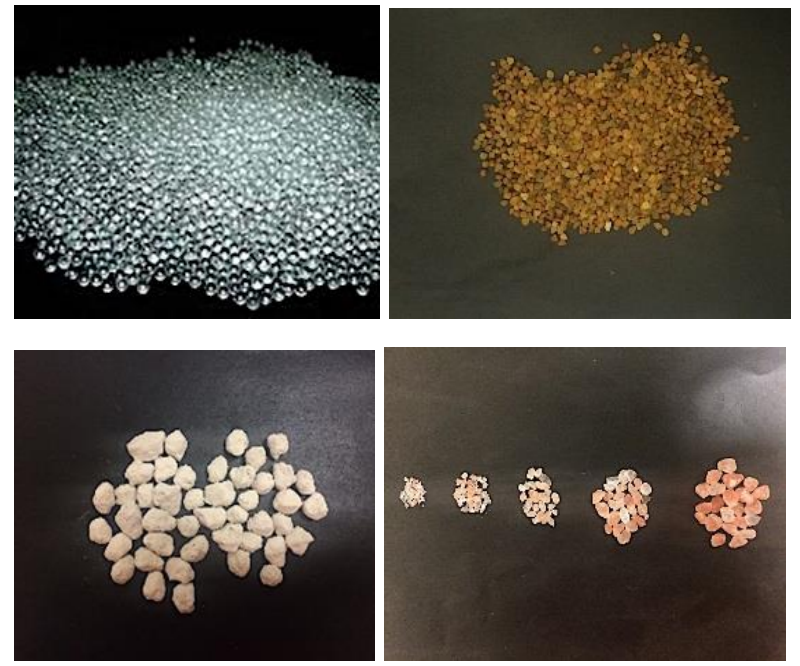

Fig. 1. Photos of bulk of the four types of materials (top-left: glass beads; top-right: Leighton Buzzard sand; bottom-left: chalk; bottom-right: salt)
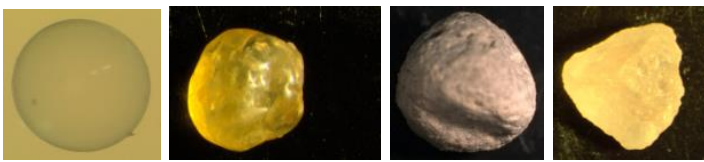

Fig. 2. Microscope photos of the four material particles; from left to right: glass, silica, chalk and salt
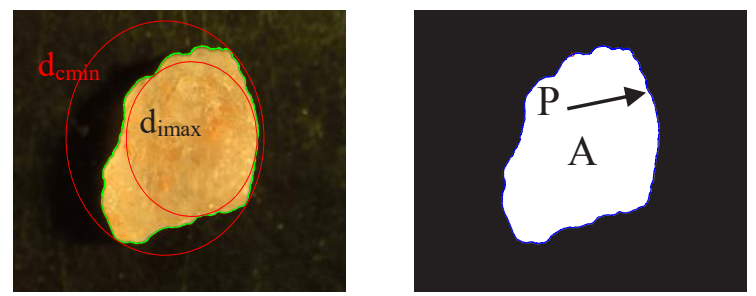

Fig. 3. Shape analysis of a salt particle (picture of particle 2D projection) and the main parameters used for the calculation of the shape descriptors as defined by (1), (2) and (3) relations

A digital microscope was employed in the analysis of the particle shape. For each particle, 2D microscope pictures from six different positions were used to generate the average values of the shape descriptors. 2D microscope pictures of single particles of the four materials used in this work are shown as an example in Figure 2. An example of a 2D picture of salt chalk particle presenting $\mathrm{A}, \mathrm{P}, \mathrm{d}_{\text {imax }}$ and $\mathrm{d}_{\mathrm{cmin}}$ parameters is shown in Figure 3 .

The values of the equivalent area diameter $\left(d_{a}\right)$ of the four types of particles are given in Table 1. The silica sand (LB) particles can be described as very low to high circularity, while its irregularity can be grouped in two categories ranging between (i) triangle and quadrangle (IR between 0.5 and 0.707 ) and (ii) quadrangle and hexagon (IR from 0.707 to 0.866 ), Figure 4a. For chalk particles (Figure 4b) the circularity measurements are mostly between "low circularity", and "high circularity", while the irregularity is mainly between quadrangle and hexagon. The circularity of the salt particles is similar to chalk particles, but the irregularity index seems to locate more between 0.6 and 0.8 (Figure 4c).

\subsection{Test setting}

The uniaxial compression test on individual particles was conducted using a displacement controlled electromechanical loading frame (Figure 5). Each particle is loaded between two rigid steel platens, of which one (top platen) is attached to a fixed loading ram that incorporates an LVDT for vertical displacement measurements and a 5 $\mathrm{KN}$-load cell. The bottom platen moves upwards at a constant displacement-controlled speed. The displacement rate for all the tests was fixed at $0.05 \mathrm{~mm} / \mathrm{min}$.

Table 1. Equivalent area diameter, $d_{a}$, of the four tested materials

\begin{tabular}{|c|c|c|c|c|c|c|c|c|c|c|c|c|c|}
\hline & \multicolumn{10}{|c|}{ Number of tests in each size group } \\
\cline { 2 - 13 } Material & $1 \mathrm{~mm}$ & $2 \mathrm{~mm}$ & $2.5 \mathrm{~mm}$ & $3 \mathrm{~mm}$ & $3.5 \mathrm{~mm}$ & $4 \mathrm{~mm}$ & $5 \mathrm{~mm}$ & $6 \mathrm{~mm}$ & $7 \mathrm{~mm}$ & $8 \mathrm{~mm}$ & $10 \mathrm{~mm}$ \\
\cline { 2 - 12 } & \multicolumn{10}{|c|}{ total number in each group } \\
\hline glass & 6 & & 6 & & 6 & 6 & & 7 & & & \\
\hline silica & & 60 & & & & & & & & & \\
\hline chalk & & 26 & & & & & 20 & 15 & 20 & 15 & 14 \\
\hline salt & 10 & 10 & & 10 & & & 10 & 10 & & & \\
\hline
\end{tabular}




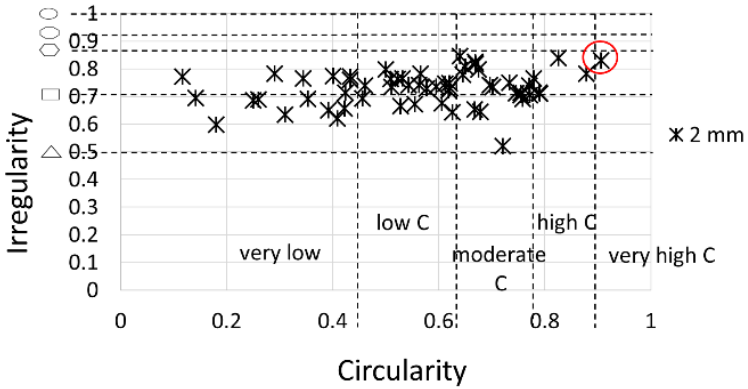

(a)

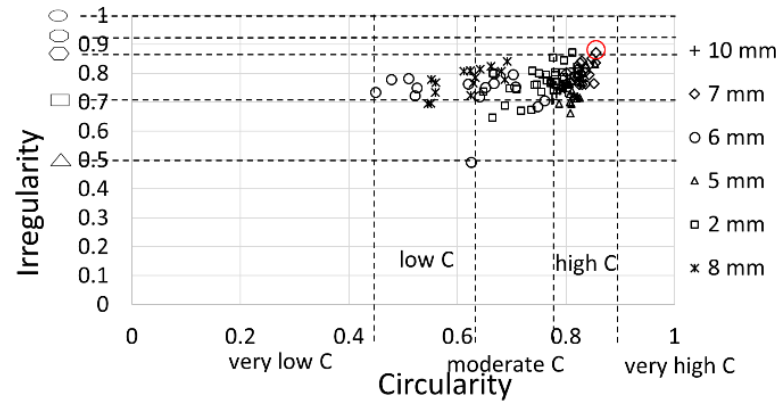

(b)

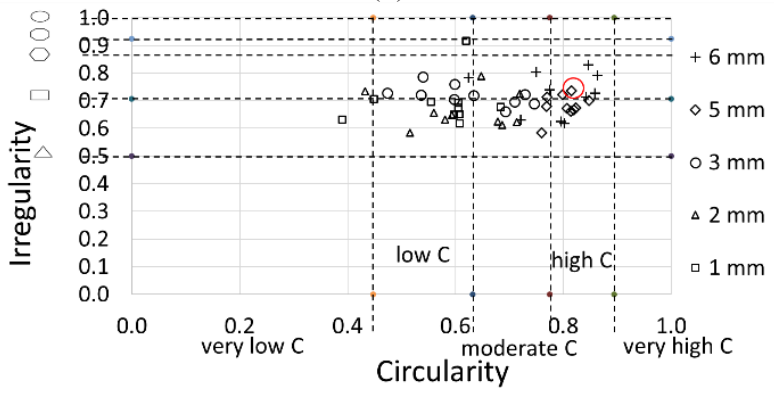

(c)

Fig. 4. Irregularity and Circularity of tested particles: (a) silica, (b) chalk and (c) salt

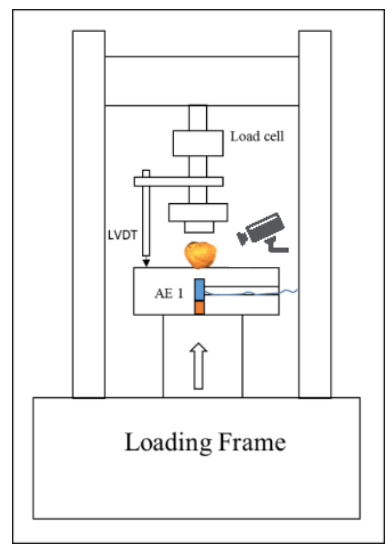

Fig. 5. Loading system and uniaxial compression test set up

During the particle crushing test, a piezoelectric sensor with a bandwidth between $10 \mathrm{kHz}$ and $1 \mathrm{MHz}$ recorded the acoustic emission (AE) signals. The AE sensor (AE 1) is fixed within the steel base platen, just below the particle at a depth of about $1 \mathrm{~cm}$, using a mechanical system that ensures a constant holding force (Figure 5). Silicon grease is also used as a coupler. Before each test, the pencil lead breakage test was conducted to check the AE sensor's response. The AE signals recorded by the $\mathrm{AE}$ sensor is pre-amplified and then sent to a high- resolution data acquisition unit. Considering the environmental laboratory noise, a threshold value of the AE signal was fixed for all the tests, as shown in Table 2. Other relevant AE system setting parameters, sampling rate (in MSamples/s), recording signal length in kilobyte $(\mathrm{K})$ and the set pre-amplifier gain $(\mathrm{dB})$ are also given in Table 2. A conventional video camera focused on the particle, which establishes the connection between the observed particle crushing patterns, force-displacement response and the

AE activity completes the testing setup system. However, not all the tests were recorded on camera. Considering the sudden violent crushing response of the glass and silica particles, only the chalk and salt particles were video recorded.

Table 2. The Relevant Parameters of Test Setting

\begin{tabular}{|c|c|c|c|c|}
\hline Material & Glass & Silica & Chalk & Salt \\
\hline Sampling rate (MS/s) & 1 & 5 & 1 & 1 \\
\hline Recording length (K) & 5 & 5 & 1 & 5 \\
\hline Preamplier gain (dB) & 20 & 40 & 40 & 20 \\
\hline Threshold of detection (dB) & 40 & 40 & 38 & 40 \\
\hline
\end{tabular}

\section{Results \& Discussion}

\subsection{Mechanical Behaviour}

In the uniaxial loading tests of glass particles, no notable changes or visible cracks in the glass sphere particles are observed as the axial force increases. Once the force reaches the maximum strength limit of the glass sphere particle, without any forewarnings, the particle explodes violently into many small fragments in all directions, with no possibility to collect them. The recorded vertical force also entirely reduces to zero (Figure 6). However, LoboGuerrero \& Vallejo [22] managed to recover the glass pieces, and as it is shown in Figure 7a, the resulted sizes of the broken pieces cover a very wide range.

Similarly, the crushing of the silica particles under one-dimensional compression loading took place without any warning and resulted in several fragments (Figure 7b) while the vertical loading rapidly decreased to zero too (Figure 6). However, some of the silica particles experienced local breakages (chipping) of the edges and corners in the initial phases of the loading.

Unlike the brittle behaviour of glass and silica particles, the chalk particles showed a more ductile response (Figure 6) and the crushing resulted in a production of a number of sub-particles (Figure 7c). In principle, for most chalk particles, the breakage in onedimensional compression could be characterized by a combination of three mechanisms: (i) minor cracks localized at the particle top or bottom close to the loading boundaries, called crumbling [23]; (ii) chipping of particle 
edges or corners; and (iii) the major crushing stage, which results in particle failure. The crumbling, chipping, cracking and breaking events do not always appear successively; for most of the particles tested, the crumbling and chipping seemed to occur at the initial stages of the uniaxial loading.

Salt particles showed a typical ductile material response during the uniaxial compression loading. With the loading increases, the colour of the salt particle changed from transparent into muddy and then turned into white with expanding, eventually disintegrating into several fragments (Figure 7d) or a fine powder. The change of the particle colour with the loading has also been observed during the testing of silica particles by Wang \& Coop [24]. Most of the force-displacement responses show a slow rate increase followed by reaching a plateau for large displacements (Figure 6), before the final crushing. The salt particle seems to experience a weakening of the material compound but retains its shape throughout the loading [23].

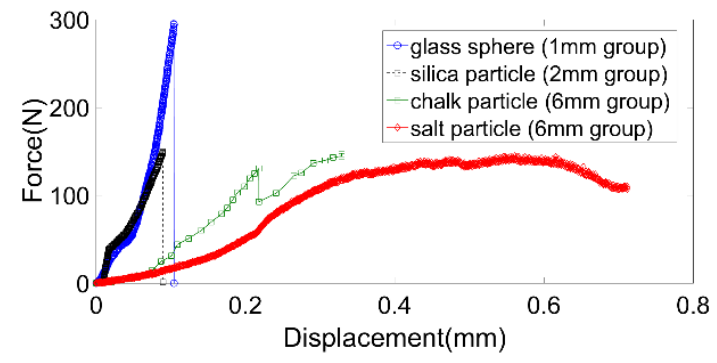

Fig. 6. Force-displacement response recorded during crushing of the four materials

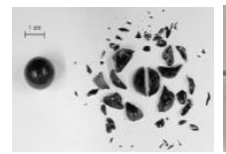

(a)

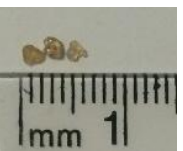

(b)

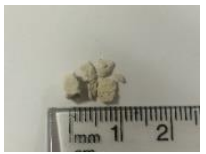

(c)

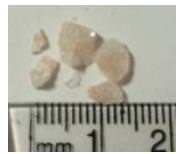

(d)
Fig. 7. Crushed fragments of the four type material particles: (a) glass fragments, after [22], (b) silica fragments, (c) chalk fragments, (d) salt fragments.

\subsection{AE analysis}

Figure 8 shows a selection of the AE signals recorded at the particle crushing point for all particle types. Although there is no apparent loading drop or dramatic failure of the axial force for the salt particles, high amplitude AE signals were recorded once the curve down-sloped gently. The way in which the particles are crushed is reflected by the appearance of the $\mathrm{AE}$ recorded signals: the most violent events of glass and silica particles generate waves of high amplitude and low rate of decay over the recording period, while the more soft materials, chalk and salt, give signals of relatively lover amplitudes that attenuate at a faster rate.

\subsubsection{Particle Size Effect}

Figure 9 shows, for a given material, comparisons between the $\mathrm{AE}$ signals recorded at the failure point for particles of different sizes analysed in the frequency domain based on Welch's power spectral density estimate method [25]. The particles have different equivalent area diameter $\left(\mathrm{d}_{\mathrm{a}}\right)$ - but similar particle shapes (Circularity and Irregularity). The AE signal strength is normalised by the maximum signal strength. For a given material, the peaks of the power spectral density estimates of the AE signals seem to appear at almost the same frequencies which signify that the $\mathrm{AE}$ frequency distribution of the $\mathrm{AE}$ signals at the crushing point of these particles of similar shape is not affected by the particle size.
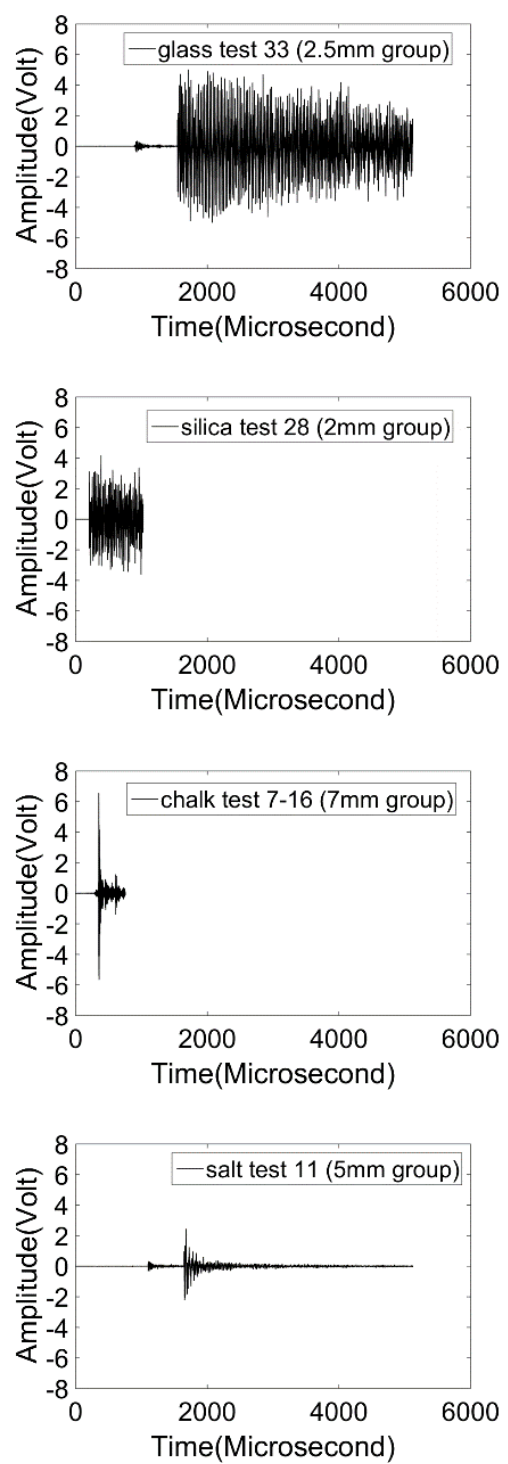

Fig. 8. AE waveforms of the critical crushing of the four types materials particles 

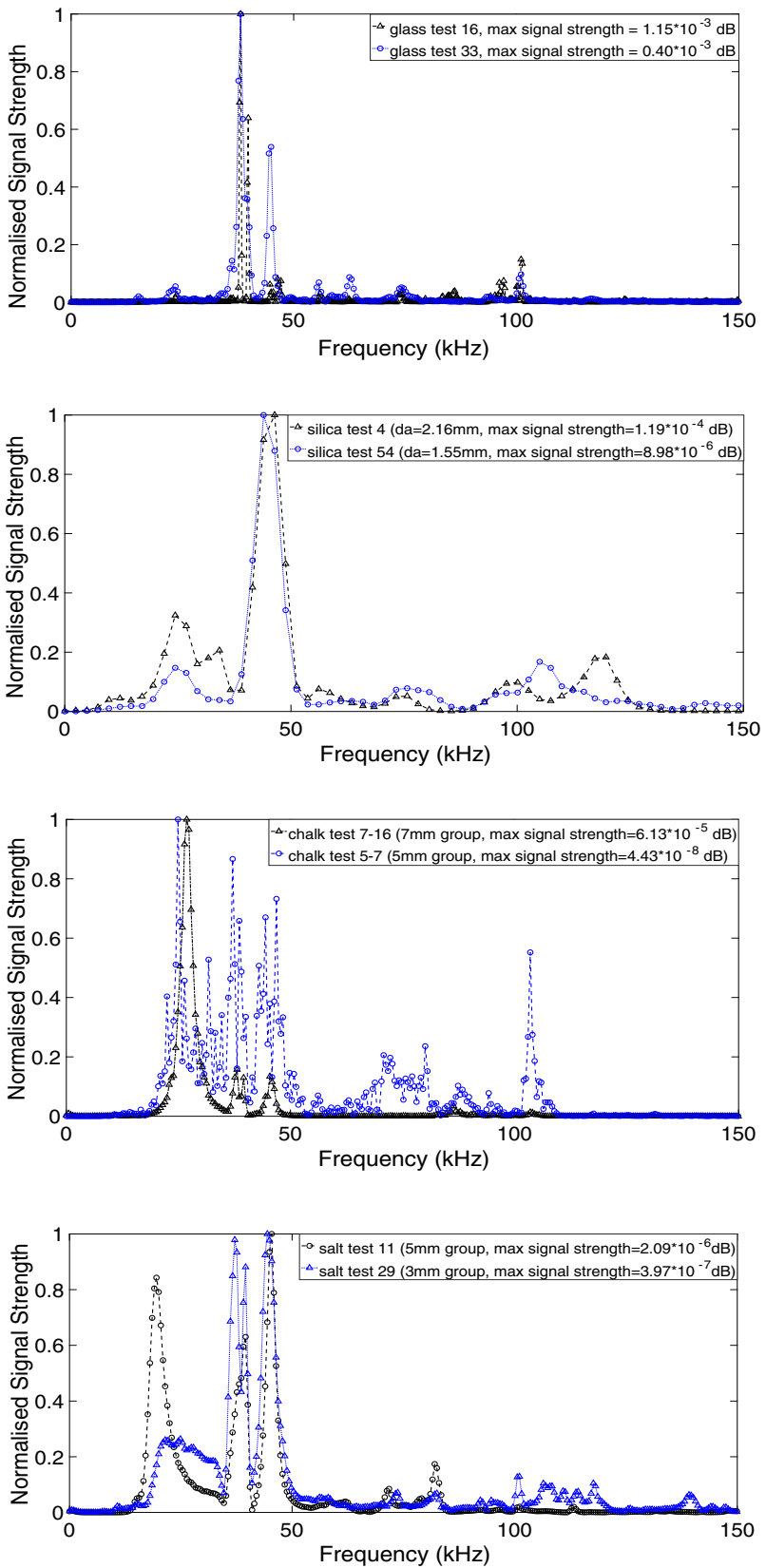

Fig. 9. Frequency distribution of the crushing AE signals in four material particles (with different size)

\subsubsection{Material type effect}

The effect of the material type on the nature of the AE signal can also be observed from Figure 9. For strong particles, the peak frequencies are grouped over a narrow range compared with the weaker particles where the peak frequencies are displayed over a wider frequency range. Figure 10 presents the power spectral density estimates of the AE signals recorded at the crushing point for four particles of different materials having as close shape as possible. The selected particles with the shape descriptors close to the spherical particles are shown in Figure 4 (red circles). It could be noticed that the signal strength of the small size glass sphere is much higher than that of the salt particle with larger size. The most rigid materials have higher AE signal amplitude compared with the soft ones. A better comparison of the peak frequencies shown for each particle using the normalisation process is presented in Figure 11. Different peak frequencies are emerging for different material types, and as expected, the peak frequencies for the glass sphere and silica particles seem higher than that for the chalk and salt particles.
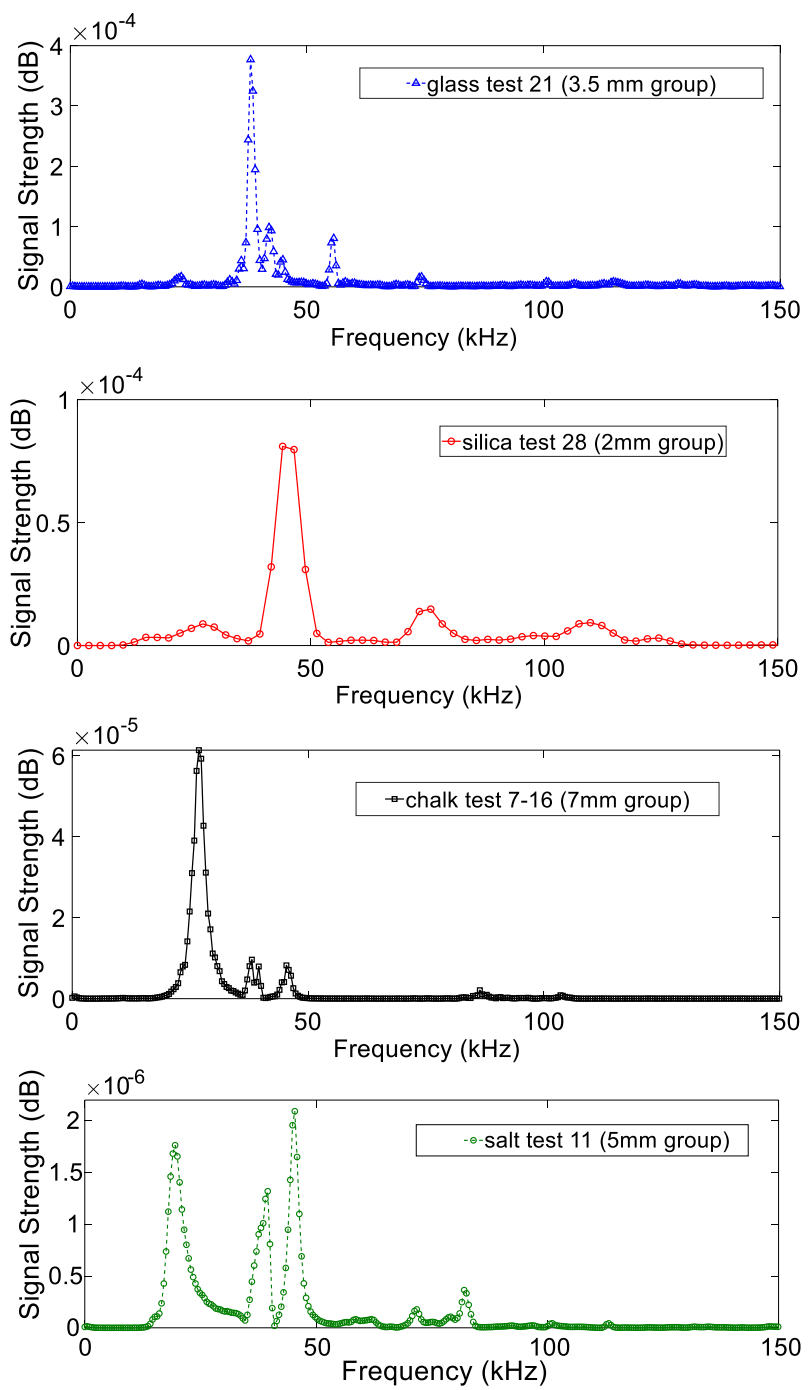

Fig. 10. Frequency distribution of crushing AE signals for four different material type particles

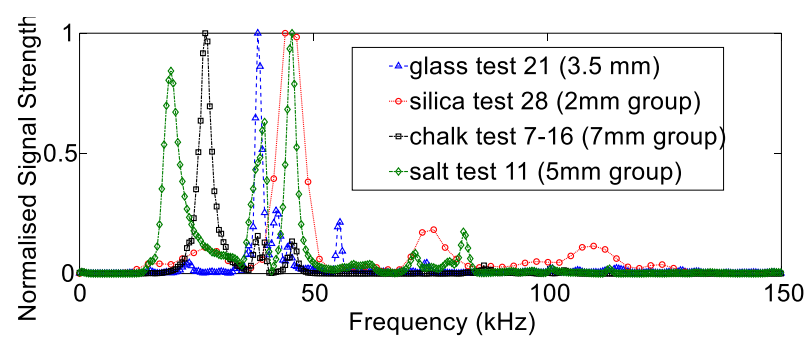

Fig. 11. Normalised frequency distribution of crushing AE signals for four different material type particles

\section{Conclusion}

In this study, the particle crushing behaviour of four materials is explored and linked with $\mathrm{AE}$ passive monitoring. It is shown that the AE technique detects and can be associated with various crushing mechanisms of the single particle under uniaxial compression. Moreover, 
the effect of the particle size on the AE signal peak frequencies was discussed and presented. For a given material, it seems that the size of the particle does not affect the frequency composition of the $\mathrm{AE}$ signals recorded at the final crushing point. The possible material effect on the AE signals was also explored. Higher peak frequency is observed for stiffer particles, while for softer ones the peak frequency are distributed over a larger range of frequencies. Correlation between these results with data from oedometer tests on soil samples made by the same material types is part of the future work.

The first (corresponding) author would like to acknowledge the PLEXUS (Priming Laboratory EXperiments on infrastructure and Urban Systems) project, which was funded by the UK Engineering and Physical Sciences Research Council under grant EP/R013535/1. It is a collaborative project grant undertaken by researchers at the University of Birmingham, University of Bristol, University of Cambridge, Cranfield University, Imperial College London, University of Leeds, Loughborough University, University of Manchester, Newcastle University, University of Sheffield, and University of Southampton, led by Professor Chris Rogers.

\section{References}

1. P. V. Lade, J. A. Yamamuro, \& P. A. Bopp. Significance of Particle Crushing in Granular Materials. Journal of Geotechnical Engineering, 122(4), 309-316 (1996).

2. M. Bolton. The Role of Micro-Mechanics in Soil Mechanics. International Workshop on Soil Crushability, (September), 25 (1999).

3. M. F. Randolph, J. Dolwin, \& R. Beck. Design of driven piles in sand. Geotechnique 44, No. 3, 427448 (1994).

4. R. Deluzarche, \& B. Cambou. Discrete numerical modelling of rockfill dams. International Journal for Numerical and Analytical Methods in Geomechanics, 30, 1075-1096 (2006).

5. R. J. Marsal. Large-scale testing of rockfill materials, Journal of the Soil Mechanics and Foundation Engineering Division, ASCE, Vol. 93, No. SM2, 2744 (1967).

6. B. O. Hardin. (1985). Crushing of Soil Particles. Journal of Geotechnical Engineering (1985).

7. H. R. Hardy. A review of international research relative to the geotechnical field application of acoustic emissionlmicroseismic techniques. J. Acoustic Emission, 8(4), 65-91 (1989).

8. M. L. McCauley, Bulletin, Association of Engineering Geology, Vol. 2, No. 1 (1965).

9. E. E. Esmiol, Field Evaluation of the Microacoustic Detector at Senator Wash Reservoir, Report to U.S. Bureau of Reclamation, Denver, Colo. (1971)

10. R. E. Coxon and D. E. Crook, Proceedings. Second Congress in Large Dams, Q. 45, R. 30, Mexico, 527 540 (1976).

11. M. F. Leach, G. A. Rubin, and J. C Williams, Powder Technology. Vol. 19, 157-167 (1978).
12. M. F. Leach and G. A. Rubin, Powder Technology. Vol. 21, 263-267 (1978).

13. K. Tanimoto and T. Noda. Proceedings, International Conference in Soil Mechanics and Foundation Engineer, Tokyo, Vol. 1/65, 315-318 (1977).

14. A. Momber, R. Mohan, \& R. Kovacevic. Fracture range detection in hydro-abrasive erosion of concrete. Wear, 253(11-12), 1156-1164 (2002).

15. Ibraim, E, Luo, S \& Diambra, A. Particle soil crushing: passive detection and interpretation. 19th ICSMGE Seoul, 389-392 (2017).

16. Luo, S., Diambra, A., \& Ibraim, E. Application of Acoustic Emission on Crushing Monitoring of Individual Soil Particles in Uniaxial Compression Test. In Proc. of 32nd ECAET: Prague, Czech Republic, Sept, 305-313 (2016a).

17. Luo, S., Diambra, A., Ibraim, E. Particle crushing: passive detection. 1st IMEKO TC-4. Int. Workshop on Metrology for Geotechnics. Benevento, Italy, March (2016b)

18. Cavarretta I, O'Sullivan C, Ibraim E, Lings M, Hamlin S, Wood DM. Characterization of artificial spherical particles for DEM validation studies. Particuology. Apr;10(2):209-220 (2012).

19. International Standard ISO/DIS 9276, Geneva. Representation of results of particle size analysis. Part 1- 6. Part 6, 1-16 (2006)

20. S. J. Blott, \& K. Pye. Particle shape: A review and new methods of characterization and classification. Sedimentology, 55(1), 31-63 (2008)

21. M. Valdek, K. Helmo, K. Pritt, \& M. Besterci. Characterization of Powder Particle. Methods, 7, 2234 (2001).

22. S. Lobo-Guerrero, L. E. Vallejo. Discrete element method evaluation of granular crushing under direct shear test conditions. ASCE J. Geotech. Geoenviron. Eng. 131(10), 1295- 1300 (2005)

23. A. D. Salman, \& M. J. Hounslow. Particle breakage. Powder Technology, 1, 143-144, (2004).

24. W. Wang, \& M. R. Coop. An investigation of breakage behaviour of single sand particles using a high-speed microscope camera. Géotechnique 66, No. 12, 984-998 (2016).

25. P. D. Welch. The use of fast fourier transform for the estimation of power spectra: a method based on time averaging over short, modified periodograms. IEEE Trans. Audio and Electroacoust, AU-15, 70-73 (1967). 